\title{
Conceitos de ecologia aplicada: as redes neotropicais e a manutenção da biodiversidade
}

A estrutura das florestas neotropicais, determinada pelas interações animal/planta é altamente organizada. O sistema consiste de várias redes paralelas, estruturalmente semelhantes, porém taxonomicamente diferentes, baseado em grupos específicos de plantas. O mutualismo tem um papel crucial na manutençã da diversidade de um sistema. As ligações moveis são representadas por animais requeridos por muitas plantas para sua reprodução e dispersão. Mutualista-chave são as plantas que suportam os organismos de ligação e que mantêm indiretamente as redes de alimentação que dependem de ligações móveis, por toda, ou parte, da abundância de espécies. Finalmente, como as formigas controlam a taxa de herbívoros sobre diversas plantas, a existência de um mosaico de diferentes formigas dominantes, onde certas espécies criam uma forma sutil e importante de locais, é necessária.

Palavras-chave: Biodiversidade; Ecologia; Redes neotropicais.

\section{Concepts of applied ecology: neotropical networks and maintenance of biodiversity}

The structure of Neotropical forests, determined by animal/plant interactions, is highly organized. The system consists of several parallel networks, structurally similar, but taxonomically different, based on specific groups of plants. Mutualism plays a crucial role in maintaining the diversity of a system. The mobile connections are represented by animals required by many plants for their reproduction and dispersion. Key mutualists are the plants that support the link organisms and that indirectly maintain the food networks that depend on mobile links, for all or part of the abundance of species. Finally, as ants control the rate of herbivores on different plants, the existence of a mosaic of different dominant ants, where certain species create a subtle and important form of sites, is necessary.

Keywords: Biodiversity; Ecology; Neotropical networks.

Topic: Notas Científicas

Reviewed anonymously in the process of blind peer
Received: 15/07/2020

Approved: $20 / 11 / 2020$
Tainá Pellegrino Martins

Universidade do Estado do Rio de Janeiro, Brasil

tainapellegrino@outlook.com

Gustavo Aveiro Lins

Universidade Federal Rural do Rio de Janeiro, Brasil

http://lattes.cnpq.br/5173989372426437

http://orcid.org/0000-0002-0244-6925

gustavoaveiro@gmail.com

Lais Alencar de Aguiar (iD)

Comissão Nacional de Energia Nuclear, Brasil

http://lattes.cnpq.br/5785500333245448

http://orcid.org/0000-0002-1551-4085

aguiar.lais@gmail.com
Josimar Ribeiro de Almeida (iD)

Universidade do Estado do Rio de Janeiro, Brasil

http://lattes.cnpq.br/3215586187698472

http://orcid.org/0000-0001-5993-0665

almeida@poli.ufri.br
Referencing this:

MARTINS, T. P.; LINS, G. A.; AGUIAR, L. A.; ALMEIDA, J. R.. Conceitos de ecologia aplicada: as redes neotropicais e a manutenção da biodiversidade. Agriculturae, v.2, n.2, p.1-4, 2020. DOI: http://doi.org/10.6008/CBPC2674-645X.2020.002.0001 


\section{INTRODUÇÃO}

As condições relativamente estáveis e moderadas das florestas tropicais úmidas, combinadas com sua alta produtividade e estrutura vertical complexa, têm sido usadas muitas vezes para explicar a alta riqueza de espécies em tais habitats. Embora esses fatores possam constituir explicações válidas para entender as diferenças entre as regiões tropicais e as temperadas, elas são de caráter excessivamente genérico para serem utilizadas por um administrador preocupado com uma flora e uma fauna corroídas em uma reserva. Em cada local, é necessário entender os componentes específicos da diversidade dentro de um habitat específico, podendo assim descobrir os elementos de controle e, se necessário, manipulá-los. É possível identificar quatro comportamentos estritamente bióticos, provavelmente comuns à maioria dos ecossistemas terrestres, de importância fundamental para entender e administrar a massa da diversidade das espécies neotropicais. A síntese adiante apresentada emerge do trabalho de numerosos pesquisadores independentes. Os quatro aspectos chave na organização de florestas tropicais, serão discutidos nesta ordem: o mosaico químico e as redes tropicais co-evoluidas; ligações móveis e mutualistas chave (ALMEIDA et al., 2019).

\section{RELATO}

Essas interações ocorrem em um conjunto de micro habitats, definidas pela dimensão do distúrbio e do estágio de sucessão. Muitos organismos chave no sistema são restritos a um micro-habitat, enquanto outros, especialmente as ligações móveis, dependem da disponibilidade constante de vários outros. A necessidade da administração das taxas de distúrbio em reservas neotropicais, por sua vez, é maior em áreas com menor relevo topográfico e menor tamanho. A cor verde relativamente uniforme da vegetação disfarça sua verdadeira natureza, na perspectiva dos herbívoros. As florestas tropicais, por exemplo, são mosaicos extremamente complexos, com respeito à sua variedade interespecífica em compostos secundários (alcaloides, terpenos etc.), substâncias químicas que servem, possivelmente, à função defensiva das plantas. Consequentemente, muitos insetos herbívoros desenvolveram especializações sensoriais e digestivas que restringem sua dieta a uma fração quimicamente semelhante das espécies disponíveis de plantas. Por exemplo, alguns besouros se alimentam de sementes de uma só árvore, talvez por sua causa de extrema especialização digestiva requerida para lidar com sementes altamente tóxicas. Um desempenho importante do mosaico químico é o fato de que plantas do mesmo gênero ou família muitas vezes alteram vários de seus componentes, assim como os insetos especializados em tratar com os seus compostos. Uma grande fração de insetos herbívoros, junto com seus parasitoides, é assim organizada dentro de redes alimentares separadas. Essas redes ocorrem lado a lado, porém estão baseadas em compartimentos diferentes, delimitados química e taxonomicamente, da produção primária (ALMEIDA et al., 2013).

\section{DISCUSSÃO}


A referência e tais sistemas como 'redes tróficas co-evoluidas', reflete o reconhecimento dos modelos do mosaico químico (e assim da alimentação do inseto), que tem sido e continuará a ser grandemente gerado por um processo de co-evolução entre plantas e seus parasitas, é possível ainda que os insetos sejam diversificados em relação a um mosaico químico. Conforme alguns autores, 'comunidade componente' ou 'rede de fonte de alimento' podem ser termos preferidos por aqueles que desejam usar uma terminologia mais neutra na discussão de subestrutura de ecossistema. Sem levar em conta como a subestrutura de um ecossistema evoluiu, o fato importante para a Biologia da Conservação é que grande parte da diversidade total de espécies numa floresta tropical será achada em muitas redes de alimentos paralelas, hospedeiro-restritas, semelhantes em organização de nutrientes, porém diferentes taxonomicamente. Se identificarmos como a diversidade é mantida dentro de uma amostra representativa das centenas de subsistemas, identificaremos as regras gerais para o trato de muitas espécies que ainda não conhecemos ou de que pouco sabemos. Somente uma pequena fração de espécies neotropicais conhecidas de Passifloraceae ocorrem numa dada flora local. Além disso, a diversidade desta família vegetal em cada local é notadamente constante, localizada em pontos da floresta neotropical úmida, variando entre 10 e 15 espécies. Tudo indica que está consistência reflete combinações de micro habitats e polinizadores que suportariam localmente diferentes espécies de Passiflora. Outras categorias de espécies de ligações móveis se referem à presença de nectários extraflorais, que atraem predadores e parasitoides (formigas, vespas, micro himenópteros) e servem de hospedeiros para outros insetos. Alguns desses visitantes são reconhecidos como importantes, como fatores de mortalidade dos insetos que atacam essas plantas. Enquanto os parasitoides, altamente especializados, são considerados parte da rede alimentar co-evoluída, os predadores, tais como formigas e vespas, se alimentam de muitas espécies de plantas foliadas, que dispõem de pecíolos nectários formando outro tipo de conexão entre redes alimentares baseadas em hospedeiros. Nos locais onde a floresta tropical foi substituída por pastagens, ambas as redes de alimentos ainda estão presentes. Entretanto, desaparecem aquelas espécies que dependem da heterogeneidade espacial do habitat. Tais espécies parecem declinar com os estágios sucessionais, dando local às florestas clímax (desenvolvidas). Entretanto, como os arbustos são menos resistentes para sobreviver na sombra do que as trepadeiras, à medida em que a floresta cresce, espera-se que a rede de alimentação da Solanaceae decline em diversidade, mais rapidamente que que a rede Passifloraceae.

\section{CONSIDERAÇÕES FINAIS}

Com base em amostras de comunidade, as heliconiides representam de 2 a $5 \%$ e as ithomiines, de 5 a $11 \%$, do total de borboletas na floresta neotropical úmida. Juntas, elas são os mais importantes modelos para vários complexos de mimetismo de borboletas, sendo que a perda de tais espécies pode acarretar drástico impacto sobre muitas espécies comestíveis e miméticas de uma determinada área. Portanto, um esquema de manejo que mantenha os trechos sucessórios ajudará a preservar uma taxa equivalente de 7 a $16 \%$ da fauna de borboletas. Ainda mais, desde que muitas espécies de plantas demonstram padrões de diversidade ecológica e morfológica semelhantes às da Passifloraceae e da Solanaceae, deduzimos que uma 
grande fração (porém desconhecida) da diversidade de plantas e dos insetos poderia ser mantido, graças a um manejo planejado, específico, para essas duas redes de alimentação.

\section{REFERÊNCIAS}

ALMEIDA, J. R.; SILVA, C. E.; SILVA, C. V. V.; AGUIAR, L. A.; GARCIA, V. S.; SOUZA, C. P.; LENZ, E. R. S.; LINS, G. A.;

ALMEIDA, S. M.. Multifatorialidade em saúde ambiental. Environmental Scientiae, v.1, p.26-47, 2019. DOI: https://doi.org/10.6008/CBPC2674-6492.2019.002.0002
ALMEIDA, J. R.; SILVA, C. E.; RODRIGUES, M. G.. Evaluation of the environmental impacts caused by deforestation in the hydric regimen of the metropolitan region of Petrópolis (RJ), Brazil. Engineering Sciences, v.1, p.14-21, 2013. DOI: https://doi.org/10.6008/ESS2318-3055.2013.001.0002

A CBPC - Companhia Brasileira de Produção Científica (CNPJ: 11.221.422/0001-03) detém os direitos materiais desta publicação. Os direitos referem-se à publicação do trabalho em qualquer parte do mundo, incluindo os direitos às renovaç̃os, expansões e disseminações da contribuiç̃o, bem como outros direitos subsidiários. Todos os trabalhos publicados eletronicamente poderão posteriormente ser publicados em coletâneas impressas sob coordenação da Cognitionis Publishing, da Companhia Brasileira de Produção Científica e seus parceiros autorizados. Os (as) autores (as) preservam os direitos autorais, mas não têm permissão para a publicação da contribuição em outro meio, impresso ou digital, em português ou em tradução. 